\title{
DUAL CODING THEORY AND EDUCATION
}

\author{
Allan Paivio \\ University of Western Ontario
}

Draft chapter for the conference on "Pathways to Literacy Achievement for High Poverty Children," The University of Michigan School of Education, September 29-October 1, 2006.

This chapter presents a dual coding theoretical and prescriptive analysis of early education in "ordinary" and impoverished environments. The first of two parts begins with the historical background of two intellectual solitudes that eventually came together in dual coding theory (DCT), followed by a summary of the theory and supporting evidence. The second part focuses on a developmental DCT hypothesis that bears most directly on educational applications relevant to the theme of this conference volume. I draw especially on a recent update and extension of DCT (Paivio, 2006) as well as earlier publications relevant to education (e.g., Clark \& Paivio, 1991; Sadoski \& Paivio, 2001).]

\section{Historical Background}

Dual coding theory has its roots in the practical use of imagery as a memory aid 2500 years ago (Yates, 1966). The memory emphasis evolved into broader applications of imagery aimed at accelerating the acquisition of knowledge. Language was always implicated but became explicitly involved as an educational partner when imagery began to be systematically externalized as pictures. The language emphasis increased during the Renaissance when influences from imagery mnemonics systems and formal logic brought words and things together in a "new logic" in which language was intended to mirror the structure of the world (Rossi, 2002). Religious iconoclasm and other influences raised doubts about the efficacy and morality of imagery and elevated language to the dominant position that it still occupies in education. Modern empirical evidence led to a revival of imagery and the beginnings of an educationally relevant DCT. The following summarizes some of the main events and players in this long drama.

The apex of the imagery mnemonic tradition was Giordano Bruno's $16^{\text {th }}$ century occult memory system (Yates, 1966), which sought to unify earthly knowledge and the supercelestial world of ideas using variants of the ancient method of loci linked to magical star-images organized according to the associative structure of astrology. For example, one Brunian method combined (a) a square architectural system of rooms subdivided into places for storing images 
of everything in the physical world with (b) a round "Lullian" memory device (Yates, 1966, pp. 173-198), in which moveable concentric wheels were used like a slide ruler to combine different subjects and predicates to generate new propositions. Bruno's version of the round system contained the celestial figures and images that were to animate, organize, and unify the earthly images contained in the memory rooms.

Bruno's writings directly inspired Tommaso Campanella's (1602) philosophical utopia, The City of the Sun, in which images externalized as pictures were used entirely for educational purposes. In the story, the city itself serves as the basis for the classical mnemonic system. Earthly knowledge is represented in innumerable pictures and explanations that adorn outer walls, temples, and galleries of the city. There are mathematical figures; pictures of the seas and rivers; specimens of minerals, trees, herbs, wines, and animals of all kinds; representations of weather phenomena; depictions of mechanical arts and historically important people. Teachers provide verbal instruction by reading aloud explanatory verses that accompany the pictures and by reading from one great book. We see later that it is not much of a conceptual stretch to interpret Campanella's pictorial-verbal educational system in dual coding theoretical terms.

The great educational pioneer, Jan Amos Comenius, took the further step of concretizing Campanella's instructional system in actual pictures and descriptions. His book Orbis Sensualium Pictus ("The world explained in pictures") was the mother of all children's picture textbooks. First published in Nuremburg in 1658, it has been used over the past three centuries as the model for more than 200 editions in twenty six languages. The Orbis was intended as a visual textbook for learning Latin and other languages. It contains none of the occult elements of its imagery ancestors but is instead a straightforward summary of the world in 150 pictures with titles. The objects in the pictures are numbered and accompanied by parallel columns of labels and short sentences describing the numbered objects, thus explaining about two thousand words from different domains (astronomical, animal. plant, occupations, abstract "notions").

The Orbis reflected Comenius' commitment to concretization as an educational method. He argued that teachers must enable children to have direct experience with things, for "things are essential, words only accidental; things are the body, words but the garment; things are the kernel, words the shell and husk. Both should be presented to the intellect at the same time, but particularly the things, since they are as much objects of understanding as is language" (Comenius, 1896 translation, p. 267; cited in Piaget, 1993).

Dual coding theory and its educational implications parallel the historical 
emphasis on concretization of knowledge through imagery and pictures. However, the mnemonists who inspired Campanella and Comenius learned about the effectiveness of imagery from their own experiences and historical anecdotes. They did not know whether it worked better than verbal methods advocated over the centuries. Moreover, although Comenius envisaged a full-scale science of education, he did not develop that science even as applied to the concretization principle he espoused. Today we have ample scientific evidence and a more explicit theoretical framework in which to embed the facts.

\section{Dual Coding Theory}

Cognition according to DCT involves the activity of two distinct subsystems, shown in Figure 1, a verbal system specialized for dealing directly with language and a nonverbal (imagery) system specialized for dealing with nonlinguistic objects and events. The systems are assumed to be composed of internal representational units, called logogens and imagens, that are activated when one recognizes, manipulates, of just thinks about words or things. The representations are modality -specific, so that we have different logogens and imagens corresponding to the visual, auditory, and haptic (feel), and motor properties of language and objects. The representations are connected to sensory input and response output systems as well as to each other so that they can function independently or cooperatively to mediate nonverbal and verbal behavior. The representational activity may or may not be experienced consciously as imagery and inner speech.

The theory means that both systems are generally involved even in language phenomena. The verbal system is a necessary player in all "language games" but it is sufficient in only a few. In the most interesting and meaningful ones, the verbal system draws on the rich knowledge base and gamesmanship of the nonverbal system. Conversely, the nonverbal system cannot play language games on its own, but it can play complex nonverbal "solitaire." The verbal system dominates in some tasks (crosswords is a simple example) and the nonverbal imagery system in others (e.g., jigsaw puzzles). Cognition is this variable pattern of the interplay of the two systems according to the degree to which they have developed.

The modality-specific nature of DCT distinguishes it from more abstract, common coding theories of cognition. Theories that emphasize the dominance of language arose from religious and educational opposition to imagery during the Renaissance. Such theories peaked in modern behaviorist interpretations of thought as inner speech. Another class of common coding theories postulate abstract mental entities and processes, usually called propositions or schemata. 
More complex hybrid theories are essentially augmented forms of dual coding in which verbal and nonverbal representations are connected to an abstract conceptual system of some kind. Much research has been directed at testing DCT against the alternatives.

\section{Empirical Evidence}

DCT research focused initially on memory and soon expanded to other cognitive phenomena. Memory remains crucial, however, because it is the basis of all knowledge and thought.The memory emphasis is further justified here because learning and memory are at the heart of educational goals.

Especially important for DCT and its applications are the beneficial effects of concreteness and imagery on memory (reviewed in Paivio, 2006, Chapter 4). In regard to concreteness, memory performance generally increases uniformly from abstract words (e.g., truth, justice), to concrete words (e.g., chair, lobster), to objects (or their pictures). In the case of language, the concreteness effect occurs with materials ranging in length from words, to sentences, to long passages, with concrete memory exceeding abstract memory performance by a $2: 1$ ratio on average. The concreteness advantage is even more striking in associative memory tasks in which recall of response items is cued by concrete stimulus words or by pictures.

The effects can be explained by two DCT hypotheses. One hypothesis is that nonverbal and verbal codes, being functionally independent, can have additive effects on recall. For example, participants in free recall experiments are likely to name presented objects covertly and thus create a nonverbal (pictorial) and a verbal memory trace. They can also set up a dual verbal-nonverbal memory trace by imaging to concrete words, but this is somewhat less likely than naming pictures, hence the lower memory for concrete words than pictures. Abstract words are difficult to image and hence are least likely to be dually coded. The expected additive memory benefit of dual coding has been confirmed in numerous experiments (e. g., Paivio, 1975; Paivio \& Lambert, 1981), which also suggested that the nonverbal code is mnemonically stronger (contributes more to the additive effect) than the verbal code.

The further benefit of cuing recall by concrete stimuli was predicted from the DCT conceptual peg hypothesis, which states that compound images that link pairs (e.g., monkey-bicycle imaged as a monkey riding a bicycle) are formed during presentation and are reinstated during recall by a concrete stimulus (e.g., monkey), thereby increasing the probability of recalling the response (bicycle). The prediction was first confirmed strongly (Paivio, 1965) using concrete (C) and abstract (A) nouns paired in every stimulus-response combination (CC, CA, AC, 
AA). The results showed that stimulus concreteness had a much stronger beneficial effect (accounting for eight times more recall variance) than concreteness of the to-be-recalled responses. The general pattern was replicated with additional controls and other materials, including variously paired pictures and words.

Begg (1972) simultaneously supported both the additivity and conceptual peg hypotheses using adjective-noun phrases that were either concrete and high in imagery value (e. g., white horse) or abstract and low in imagery value (e. g., basic truth). Participants were asked to recall individual words from the phrases, entire phrases, or one word from each phrase given the other as a cue. Begg reasoned that concrete phrases would be integrated in memory by images (e. g., of a white horse) whereas abstract phrases would be recalled as separate words, so that twice as many concrete words as abstract words would be remembered in free recall, with a further increment for concrete words in cued recall because the entire mediating image would be redintegrated by the cues. Begg's free recall results actually exceeded prediction in that recall of concrete phrases was more than double that of abstract phrases, consistent with the image superiority addendum to the code-additivity hypothesis. Moreover, in agreement with the conceptual-peg hypothesis, recall was six times higher when cued by a concrete word than by an abstract word.

It is important in the present context that the concreteness effects have been obtained with different age groups, with qualifications that are especially notable in the case of picture word comparisons. For example, language-competent young children do not recall pictures better than words in a free verbal recall task unless they are required to name the pictures during presentation. Presumably they do not spontaneously name pictures as readily as do older persons. This finding is consistent with a developmental interpretation of DCT, to be explained later on.

Even more relevant are the qualifications in associative learning tasks in which pictures can serve as stimulus or response item. The effects for children were systematically studied (Dilley \& Paivio, 1968) with nursery school, kindergarten, and first grade children. Five paired associates

(e. g., bird-shoe, hat-star) were presented in all four stimulus-response combinations of pictures and auditorily-presented words (necessary because the sample included children below reading age). Verbal recall was tested by presenting the first item of each pair and requiring the child to recall its partner verbally. Ten alternating study-test trials were given. The most striking result was that recall was much higher for picture-word pairs than for all other combinations, and lowest for word-picture pairs, even for the nursery school children. The positive effect of pictures as stimuli was consistent with conceptual peg 
hypothesis. The negative effect of pictures as responses, not obtained with adults, was predicted from the hypothesis that children would experience difficulty in decoding the memory image of an object into the appropriate verbal response.

The role of imagery and dual coding on memory have been directly studied using participants' reports of their imagery and verbal thought processes during a memory task, and by instructing them to use different strategies. Sadoski (1985) had third and fourth graders read an unillustrated basal reader story aloud and then answer a series of comprehension questions, retell the story, and report any images recalled from the story either before or after the retelling. The story included a particularly dramatic climax. Children who were questioned prior to story recall and reported a climax image recalled more of the story than those who didn't report a climax image. There was no such effect for children who recalled their imagery after recalling the story. Sadoski suggested that the climax image functioned as a conceptual peg for subsequent story recall.

In other srudies, dual coding interpretations of concreteness effects have been supported by participants' reports of selective use of imagery strategies to learn concrete material and verbal strategies to learn abstract material. Moreover, instructions to use imagery augment recall, especially for concrete language but even for abstract language if conditions encourage participants to concretize abstract words (e. g., imagine "justice" as a frocked judge).

DCT competitors explain the relevant findings in terms of abstract representations (e. g., propositions, schemata) or general structural and processing correlates of dual coding variables (e.g., concrete materials are processed more deeply, encoded more distinctively, or have more contextual support than abstract material). Recent evidence (e.g., Paivio, 2006, pp. 82-86; Richardson, 2003) continues to favor DCT over these other explanations of the critical effects. At the same time, variables emphasized in other theories have long been accepted and investigated from the DCT perspective. For example, contextual variables and distinctiveness of images have been shown to affect performance in different memory tasks in ways that were predicted from DCT. All remain relevant in educational applications of the theory.

Other behavioral and neuropsychological studies provide further relevant support for the theory. For example, Thompson and Paivio (1994) showed that object pictures and sounds had additive effects on memory, thereby supporting the DCT assumption that sensory components of multimodal objects are functionally independent. Similar effects have been demonstrated for combinations of other modalities. Brain scan studies have shown that different brain areas are activated by concrete and abstract words as well as by pictures as compared to words in 
comprehension and memory tasks (summarized in Paivio, 2006, Chapter 8). Brain scan and lesion studies have uncovered distinct representational substrates for almost every conceivable sensorimotor modality of objects and their attributes, whether accessed directly by perceptual stimuli or indirectly (cross-modally) by words (Paivio, 2006, Chapter 7). For example, words that name colors or actions activate the same brain areas as perceived colors and action patterns. Such results strongly support the functional and structural reality of multimodal imagens and logogens as described ealier--our brains apparently "contain" auditory, haptic, and motor imagens and logogens, which are housed in different locations and accessed by different neural pathways.

\section{A DCT Cognitive Developmental Hypothesis}

Cognitive growth according to DCT is based on multiple learning processes of observation, classical conditioning, operant learning, and imitation. It involves progressive elaboration of cognitive representations and processes from a nonverbal base to dual coding systems that include language as well. The salient stages are identified in the following hypothesis (from Paivio, 1971, p. 438). Dual coding development begins with the formation of a substrate of nonverbal representations and imagery derived from the child's observations and behaviors related to concrete objects and events, and relations among them. Language builds upon this foundation and remains functionally connected to it as referential connections are being formed, so that the child responds to object names in the presence or absence of the objects, and begins to name and describe them (even in their absence). The events, relations, and behaviors are dynamically organized (repeated with variations) and thereby display natural syntax that gets incorporated into the imagery as well. The natural syntax is enriched by motor components derived from the child's actions, which have their own patterning. This basic stage becomes elaborated as function words are acquired and intraverbal networks expand through usage. Abstract verbal skills are eventually attained, so that language becomes relatively autonomous, free of dependence on situational contexts and imagery.

The growth can be described more generally as a bootstrapping process in which dual coding systems pull themselves upward using their own resources, thus constituting an increasingly complex and powerful feed-forward system. The idea is compatible with the Herbartian concept of apperceptive mass, a knowledge structure that grows with experience. The concept greatly influenced education and was reflected as well in the Piagetian concepts of assimilation and accommodation of new information with schemata. The difference here is that DCT emphasizes the functional importance of the nonverbal and verbal 
components of the growing apperceptive mass (Paivio, 2006, pp. 31-32). Moreover, unlike the schema-based Piagetian concepts, the DCT sensorimotor systems are modality-specific rather than amodal and abstract.

All developmental stages are empirically supported. Nonverbal cognitive representations manifest themselves early in recognition responses (e.g., habituation) to people and objects before there is any hint of language. Language shows up later in name-related behaviors such as looking at or searching for named objects--proof of referential connections between logogens and imagens. A glimmer of autonomous verbal behavior shows up early in vocal mimicry of speech sounds, including one's own ("echolalia"), but it appears more clearly later in the verbal associative skills involved in comprehension and production of sequences of two or more words, some of which can be classified as grammatical.

The grammatical phase was supported most directly by Moeser and Bregman (1973) in an experiment in which participants learned a miniature artificial grammar with or without syntax-correlated referents. Participants who received different sentence exemplars presented only as strings of nonsense words showed no learning after 3200 trials. Those who saw the sentences along with syntaxcorrelated referent pictures showed rapid learning, and could subsequently learn new instances from verbal contexts alone. The authors noted that their results were consistent with predictions from the dual coding analysis of syntax learning just described, particularly the conclusion that "the grammars first learned by children will be 'tied to' the syntax of concrete objects and events...via the medium of imagery...and only later will more abstract grammars emerge" (Paivio,1971, pp. 437-438). Moeser and Bregman's data have been carefully rfe-examined recently from a mental- models perspective on language that is compatible with DCT (Strømnes, 2006).

\section{Educational Applications of DCT}

The developmental hypothesis is a natural bridge to the educational applications of DCT because the hypothesis contrasts with developmental assumptions that apparently underlie mainstream approaches to education in Western countries. The following section (a) spells out the educational implications of the DCT hypothesis, (b) summarizes the contrasting mainstream assumptions, and (c) reviews educational research explicitly related to DCT.

The important practical aspect of the DCT developmental analysis is its stress on the early development of the nonverbal system as the foundation for later cognitive skills that include language as well. The early development is based on sensorimotor experiences with concrete objects and events. It follows that cognitive growth depends on the richness of the early nonverbal experiences, 
increasingly associated with the language experience necessary for the development of the verbal side of a complete dual-coding mind. An important corollary is that cognitive growth will not be stimulated as effectively by a disproportionate early emphasis on language experience relative to nonverbal experience.

The early stage of the DCT analysis is consistent with general theoretical views and evidence on the effects of early experience on brain and behavioral development. The views are often traced to Hebb's (1949) suggestion that early visual experience is essential for the development of normal perception and promotes brain plasticity that facilitates learning and memory later on. These views influenced animal and human research in the 1950s and1960s, which showed that enriched early experience induced physiological and anatomical brain changes, and also improved learning and memory. However, the experienceinduced brain changes also occurred even in adult rats and humans. Moreover, they are domain specific so that. for example, early musical experience produces growth in brain areas involved in musical skills. Also relevant is the research by Ericsson and his colleagues (e. g., Ericsson, 1996) that early and sustained deliberate practice is necessary for high-level performance skills in various nonverbal as well as verbal domains. Such results suggest that enriched experience is responsible for the formation of specific nonverbal cognitive representations, such as Hebbian cell assemblies or DCT imagens, but there is no direct evidence for such interpretations.

Earlier (Paivio, 1986, p. 90), I concluded similarly that the evidence is unclear on the stronger DCT hypothesis that the growth of the verbal system depends on the richness of a nonverbal base. This is still the case, although there is some agreement on the general hypothesis. For example, McCune (2006) suggested that "Dynamic event word meanings based on pre-linguistic cognition further provide the meanings observed in verbs of early sentences" (p. 90), and Neuman (2001) emphasized the role of knowledge in early literacy. Somewhat paradoxically, McCune (2006) also proposed that that pre-linguistic cognition is "nonconceptual, with children dependent on language [dynamic event words] to mold this...early cognition toward concepts" (p. 233). The ambiguity apparently hinges on a distinction between meanings and concepts, which we need not consider (such conceptual distinctions are discussed in Paivio, 2006, Chapters 3 and 4).

The contrasting emphasis on the primacy of language experience in education programs in Western countries can be seen even in programs designed especially for socially-disadvantaged children. For example, the Head Start educational 
programs for preschoolers from low-income families in the United States have always focused on literacy, language, and numeracy skills. In their research review, Barnett and Hustedt (2005) find mixed support for lasting benefits in subsequent school achievement and only modest improvement in children's development. For example, early increases in IQ typically fade out over time. The "modest" nature of improvements could also reflect the language emphasis of the programs. As noted in the final public address by the late Michael Pressley, there is a similar emphasis in the recent No Child Left Behind (NCLB) ACT, which "favors teaching phonemic awareness, phonics, fluency, vocabulary, and comprehension strategies, with basically no mention of anything else" (Pressley, 2006, pp.7-8). He questioned whether there is an effective classroom in the United States that focused so heavily on those skills, and suggested that "It would help if efforts were made to ensure that targeted preschoolers experience the cultural activities that provide connversational opportunities for many advantaged parents and preschoolers, such as trips to zoos, museums, shows, bookstores-and even quality toy stores!" From the DCT perspective, this recommendation emphasizes experiences that particularly stimulate growth of the nonverbal side of dual coding systems.

As evidence for his recommendation, Pressley referred to a widely- cited study by Campbell and Ramey (1994). Black infants were provided with an 8-hour per day intervention involving exercises designed to enhance perceptual motor as well as cognitive and language skills. The intervention resulted in significant and lasting gains in IQ. For example, $87 \%$ of the children exposed to the intervention had IQs in the normal range at age 12 , as compared to $57 \%$ of control children.

We turn now to instructional variables and principles specifically relevant to DCT. We have seen that participants in experiments can be prompted to use imagery and dual coding variables effectively in memory and other cognitive tasks. We now ask whether such variables can be similarly helpful in "normal" and remedial school settings. Early educators certainly thought so and modern educational research justifies their recommendations. More specifically, the evidence supports the DCT prescriptive principles of fostering the development of verbal and nonverbal systems by concretizing abstract verbal information on the one hand and verbalizing to concrete information on the other. I summarize the main conclusions in regard to literacy and other skills that follow from comprehensive reviews of the research literature (Paivio, 2006, Chapter 19; Sadoski \& Paivio, 2001, Chapter 8), and focusing in more detail on specific studies that are especially pertinent to the theme of this conference.

Reading skills. Beginning readers learn to read concrete words by sight much 
faster when the words are accompanied by referent pictures than when paired only with their pronunciations. Concrete verbal material enhances reading comprehension and recall in children and adults. Concrete advance organizers (e.g., brief written texts read prior to other texts) improve comprehension and recall of instructional text. Such results presumably reflect the various contributions of concreteness-evoked imagery and dual coding to the meaningfulness, memorability, and retrievability of information in text.

Instructing learners to form images during reading further enhances reading comprehension and vocabulary learning. Combining pictures, mental imagery, and verbal elaboration is even more effective in promoting understanding and learning from text by students ranging from grade school to university level. For example, consistent with DCT, Purnell and Solman (1991) reported additive effects of text and illustrations on the comprehension of technical material by high school students . On the basis of the such results, Mayer $(1999,2001$ ?) made the following recommendations about multimedia learning: (a) use words and pictures rather than words alone, (b) present pictures and corresponding words or narrations close together in space or time, (c) minimize extraneous (irrelevant) details, and (d) present words as speech rather than on-screen text in animations (presumably to minimize modality-specific interference). These recommendations accord with the practical implications of DCT.

Written composition. The use of concreteness, imagery, and dual coding makes students' writing more readable and memorable. Such verbal associative techniques as listing relevant words that could be used in writing about a topic and practice combining sentences improve such features as organization and syntactic fluency of writing. STOPPED

Remedial literacy education. Methods that implicate dual coding principles have been used in remedial education for learning difficulties. The methods can all be classed as augmentative aids in that they supplement traditional classroom teaching methods. All make use of nonverbal stimuli and some encourage use of imagery. Remediation has traditionally focused on decoding because readers must be able to recognize printed words before they can get their meaning. Decoding ability is measured by tests that require reading words or naming letters aloud. Comprehension tests require understanding what words and text mean. It is relevant that decoding and comprehension are not highly correlated. Statistically, the respective tests cluster under two different factors (with subcategories within each). A striking example of dissociation of the two abilities is that some highfunctional autistic people (those with Asperger's syndrome) are "superlexics" who can read aloud extraordinarily well and yet not understand what they are reading. 
Lindamood-Bell Learning Processes is a private remedial education company that developed reading programs that fit well with DCT (e.g., Lindamood, Bell, \& Lindamood, 1997). Phonemic awareness is taught by associating phonemes with motor acts, pictures of the mouth, and descriptive labels (e.g., "lip poppers" for $/ \mathrm{p} /$ and $/ \mathrm{b} /$ ). The positions of the phonemes in words and longer sequences are taught using colored blocks. Comprehension is taught through a program of visualizing and verbalizing that is explicitly related to DCT (Bell, 1991). Instruction entails progressive buildup of imagery to larger and larger text segments-words, phrases, sentences, texts-with learners being encouraged to describe their images in increasing detail. Higher order comprehension involved in inference, prediction, and evaluation is dealt with through imagination and verbal elaboration. This instructional technique thus teaches learners how to concretize text using imagery and dual coding as they read.

The strongest evidence for the efficacy of the Lindamood-Bell approach comes from a multischool augmentative intervention program that particularly emphasized Visualization-Verbalization procedures. The intervention dramatically raised the reading performance of students in grades 3, 4, and 5 of low reading achievement schools in the Pueblo School District in the State of Colorado, so that the schools eventually outperformed other comparable Colorado schools in tests of reading (Sadoski \& Willson, 2006). Figure 2 shows the improvement over years for students who started in grade 3, thus demonstrating that DCT-related instructional techniques are effective with 8-year olds, the upper range of the population targeted in the present volume. In clinical settings, VisualizationVerbalization has been used successfully to improve various reading test scores with children as young as 6 years [Footnote: Personal communication from Nanci Bell, August, 2006.]

Mathematics. Clark and Campbell (1991) used dual coding mechanisms to develop a general theory of number processing, The theory emphasizes the concrete basis of number concepts and the roles of associative mechanisms and imagery in performing numerical operations. The basic dual coding processes have long been used in teaching arithmetic. Children first learn to name numerals and then their meanings by associating them with groups of objects or their pictures, They learn addition, subtraction, and multiplication concretely by adding marbles to a pile or taking them from it. They literally calculate, which derives from the Latin root that refers to small stones used in reckoning on an abacus. They learn corresponding verbal number associations by rote memorization of addition, subtraction, and multiplication tables. Productive extensions to large numbers and 
columns of numbers require the further operation of carrying products, and so on. Learning fractions builds on an understanding of division, similarly acquired by concrete examples translated into verbal /numerical operations. All of these skills entail development of increasingly long and varied representations (logogens) for number names and operators (rapid production of "two times three equals six" implies activation of a corresponding sentence-length logogen) as well as imagens of numerals and operators. Rods of different lengths and colors (Cuisenaire \&Gattegno, 1954) have been used for teaching addition, subtraction, fractions, etc., because they represent abstract relations and yet can be easily manipulated and imaged by children. Algebga is made easier by transforming equations into geometric shapes. In sum, effective mathematical education relies on appropriate concretization of abstract symbols and relations (Skemp, 1987).

Mathematician John Mighton (2003) started an an educational charity called JUMP (Junior Undiscovered Math Prodigies) for elementary school students who had experienced difficulty learning mathematics in their schools. The program involves systematic concretization of mathematical concepts and operations, many of which (e.g., use of "pie" charts and box diagrams)are familiar to all teachers. What is different in the JUMP program is that they are used systematically so that every student masters the operations as applied to one problem before moving to a more complex one. Anecdotal evidence shows that individuals and whole classes of students classified as slow learners excelled in mathematics following the JUMP intervention. More formal studies of the program are presently in the works.

In addition to its remedial reading programs already described, LindamoodBell Learning Processes has developed a remedial mathematics program (Tuley \& Bell, 1997). The program is similar to JUMP in its emphasis on concretization of mathematical operations and concepts. It differs from JUMP in that it teaches children how to use visualization (mental imagery) to represent numbers and operations. The program proceeds from (1) concrete experience using number lines, cubes, and the like, to (2) imaging the entities and operations, to (3) computation. The steps are depicted as a "math-ladder" with imaging numerals at the lowest rung and fractions at the top. Learners climb the step by step at their own pace. As in the case of JUMP, much anecdotal evidence supports the effectiveness of the LBLP math program.

\section{Whither DCT Educational Research?}

Education applications of DCT call for more systematic research on effects of dual coding variables at different age levels. Evidence is especially lacking on the importance of richness of early nonverbal experience on the development of language and cognition in general. Systematic observations and experiments 
should provide information on the number and variety of objects and events with which the child interacts, and relate these to cognitive skills that presumably reflect growth in the "imagen family" (i.e., imagens of different modalities). Direct detection of imagery skills would be possible in infants less than a year old using such tasks as visual exploration of spatial transformations (Lew, Foster, Bremner, Slavin, \& Green, 2005). The effects of early nonverbal experience on the development of vocabulary and other languages skills could be similarly studied more systematically than has been the case thus far. Direct evidence that imagery and dual coding mediate effects at this early language stage would require adapations of such tasks as selecting a named object from an array (analogues of picture vocabulary tests) or searching for an absent named object. One could also explore how early children begin to show evidence of more complex cooperative interplay of verbal and nonverbal systems, as in the Visualization -Verbalization effects already demonstrated with school- age children.

\section{References}

Arnheim, R. (1969). Visual thinking. Berkeley \& Los Angeles: University of California Press.

Barnett, W. S., \& Hustedt, J. T. (2005). Head Start's lasting benefits. Infants \& Young Children, 18, 16-24.

Begg, I. (1972). Recall of meaningful phrases. Journal of Verbal Learning and Verbal Behavior. 11, 431-439.

Bell, N. (1991). Visualizing and verbalizing for language comprehension and thinking. Paso Robles, CA: NBI Publications.

Campanella, T. (1602). The city of the sun. Retrieved February 22, 2004 from http://www.levity.com/alchemy/citysun.html

Campbell, F. A., \& Ramey, C. T. (1994). Effects of early intervention on intellectual and academic achievement: A follow-up study of children from lowincome families. Child Development, 65, 684-698.

Clark, J. M., \& Campbell, J. I. D. (1991). Integrated versus modular theories

of number skills and acalculia. Brain and Cognition, 17, 204-239.

Clark, J. M., \& Paivio, A._(1991)._ Dual coding theory and education. Educational Psychology Review, 3, 149-210.

Comenius, J. A. (1896). The great didactic. London: Adam \& Charles Black.

Cuisenaire, G., \& Gattegno, G. (1954). Numbers in colour. London: Heinemann.

Ericsson, K. A. (ed.). (1996). The road to excellence: The acquisition of expert 
performance in the arts and sciences, sports and games. Mahwah, NJ: Lawrence Erlbaum Associates.

Hebb, D. O. (1949). The organization of behavior. New York: Wiley. Hillocks, G., Jr. (1986).Research on written composition: New directions for teaching. Urbana, IL: ERIC Clearinghouse on Reading and Communication Skills and the National Conference on Research in English. Hillsdale, NJ: Erlbaum.

Lew, A. R., Foster, K. A., Bremner, J. G., Slavin, S., \& Green, M. (2005). Detection of geometric, but not topological, spatial tansformations in 6- to 12month-old infants in a visual exploration paradigm. Wiley IntScience (www.interscience.Wiley.com). DOI. 10.1002/dev.20075

Lindamood, P., Bell, N., \& Lindamood, P. (1997). Sensory-cognitive factors in the controversy over reading instruction. Journal of Developmental Disorders, $1,143-182$.

Mayer, R. E. (1999). Research- based principles for the design of instructional messages: The case of multimedia explanations. Document Design, 1, 7-20.

McCune, L. (2006). Dynamic event words: From common cognition to varied linguistic expression. First Language, 26, 233-255.

Moeser, S. D. \& Bregman, A. S. (1973). Imagery and language acquisition. Journal of Verbal Learning and Verbal Behavior, 12, 91-98.

Neuman, S. B. (2001). The role of knowledge in early literacy. Reading Research Quarterly, 36, 468-475.

__Paivio, A. (1965). Abstractness, imagery, and meaningfulness in paired-associate learning. Journal of Verbal Learning and Verbal Behavior, 4, 32-38.

Paivio, A. (1971). Imagery and verbal processes. New York: Holt, Rinehart, and Winston.

Paivio, A. (1975). Coding distinctions and repetition effects in memory._In G. H. Bower (ed.), The psychology of learning and motivation,_Vol. 9, New York: Academic Press, pp.

Paivio, A. (2006). Mind and its evolution; A dual coding theoretical interpretation, Mahwah, NJ: Lawrence Erlbaum Associates, Inc.

Paivio, A., \& Lambert, W. (1981). Dual coding and bilingual memory. Journal of Verbal Learning \& Verbal Behavior, 20, 532-539.

Piaget, J. (1993). John Amos Comenius. Retrieved February 29, 2004 from http/www.ibe.unesco.org/publicationsThinkersPdc/comeniuse.pdf.

Pressley, M. (2006, April 29). What the future of reading research could be. Paper presented at the International Reading Association's Reading Research 2006, Chicago, Illinois. 
Purnell, K. N., \& Solman, R. T (1991). The influence of technical illustrations on students' comprehension of geography. Reading Research Quarterly, 26, 277-299.

Richardson, J. T. E. (2003). Dual coding versus relational processing in memory for concrete and abstract words. European Journal of Cognitive Psychology, 15, 481-501.

Rossi, P. (2000, S. Clucas trans.). Logic and the art of memory: The quest for a universal language._Chicago: University of Chicago Press.

Sadoski, M., Kealy, W.A., Goetz, E.T., Paivio, A. (1997)._Concreteness and imagery effects in the written composition of definitions. Journal of Educational Psychology, 89, 518-526.

Sadoski, M., \& Paivio, A. (2001). Imagery and text: A dual coding theory_of reading and writing. Mahwah, N.J.: Lawrence Erlbaum_Associates.

Sadoski, M., \& Willson, V. L. (2006). Effects of a theoretically-based large scale reading intervention in a multicultural urban school district. American Educational Research Journal, 43, 137-154.

Schultz, J. (1982). Writing from start to finish. Upper Montclair, NJ: Boynton/Cook.

Strømnes, F. J. (2006). The fall of the word and the rise of the mental model: A reinterpretation of the recent research on the use of language and spatial cognition. Frankfurt-am Main, Germany: Peter Lang Publishing.

Thompson, V., \& Paivio, A. (1994)._ Memory for pictures and sounds: Independence of auditory and visual codes. Canadian Journal of Experimental Psychology, 48, 380-398.

Tuley, K., \& Bell, N. (1997). On cloud nine: visualizing and verbalizing for math. San Luis Obispo, CA: Gander Publishing.

Yates, (1966). The art of memory. London:_Routledge \& Kegan Paul. 


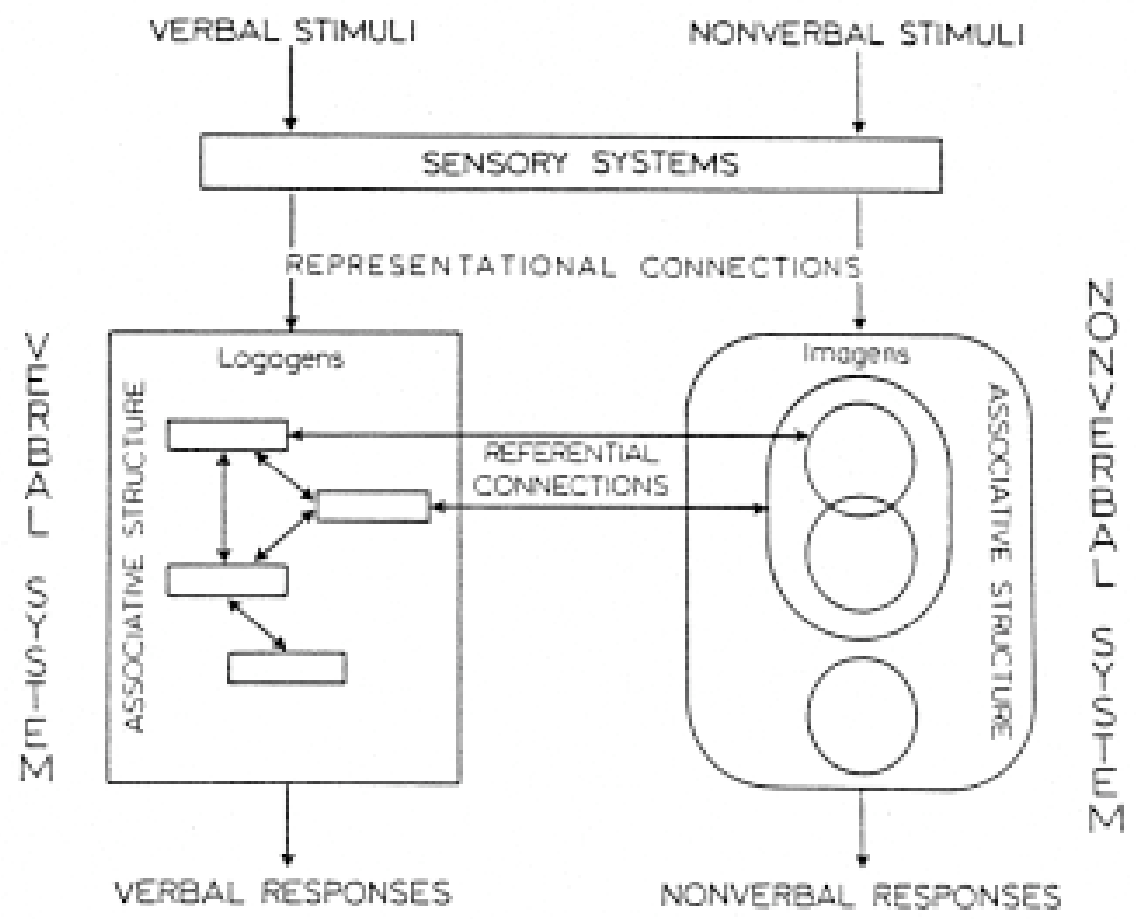




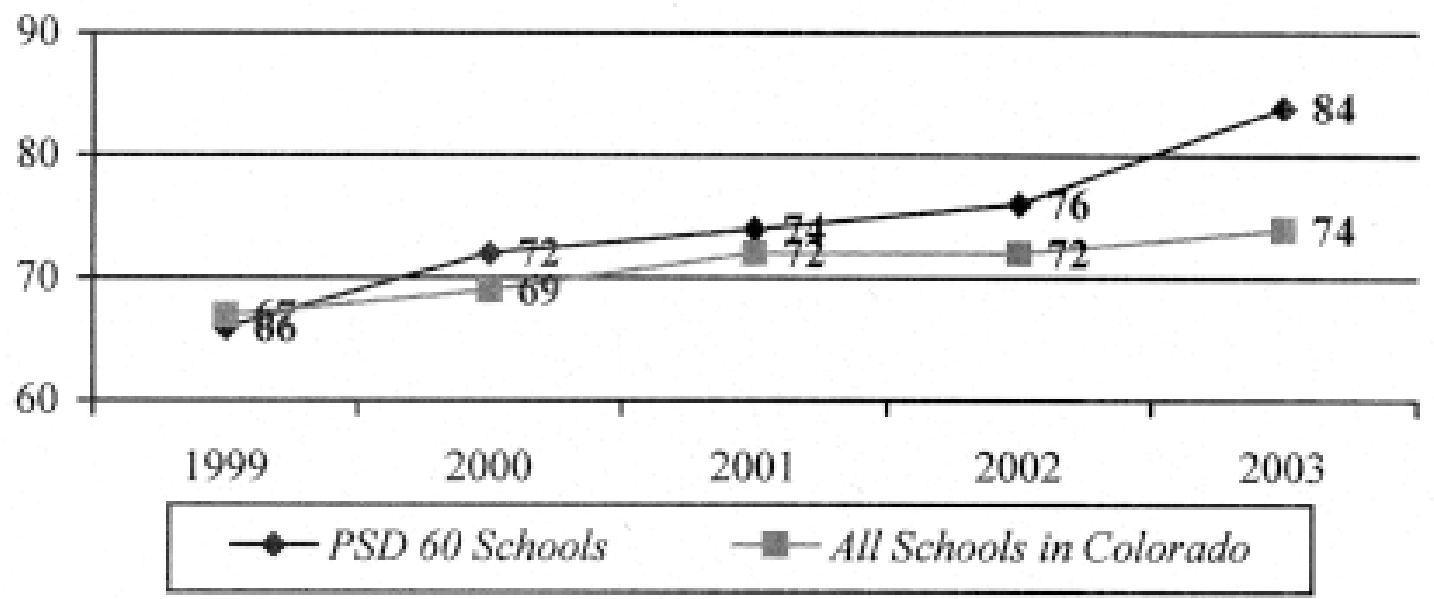

Figure 1. Structural model of dual coding theory showing the representational units and their referential and associative interconnections. The referentially unconnected units correspond to abstract-word logogens and "nameless" imagens, respectively. Figure 4-1 from Mental representations: A dual coding approach by Allan Paivio, copyright 1986/1990 by Oxford University Press, Inc. 
Figure 2. Reading performance test scores over four years for students in Pueblo School District 60 in the State of Colorado who, in grade 3, started a multischool augmentative reading intervention program using the Lindamood-Bell Learning Processes programs. Their growth curve significantly exceeds that of students in other comparable Colorado schools (Sadoski \& Willson, 2006). Based on data that are publicly available from the State of Colorado and Pueblo School District 60. 
